\title{
A Case of Pulmonary Aspergillus Infection in with a Patient Renal Failure
}

Şahin $\mathbf{R}^{*}$

Mersin City Hospital, Mersin, Turkey

*Corresponding author: Șahin R, Mersin City Hospital, Mersin, Turkey

Received: January 07, 2019; Accepted: January 24, 2019; Published: J anuary 31, 2019

\begin{abstract}
Invasive aspergillosis caused by Aspergillus spp is seen in immunocompromised hosts and has a poor prognosis. We report a case of pulmonary aspergillosis in a 84-year-old male who had cough, respiratory distress symptoms and a history of primary hypertension, chronic obstructive pulmonary disease, and unspecified chronic renal failure. In the microscopy of deep tracheal aspirate specimen taken from the patient was seen rare leukocytes (PMNL), 1-2 epithelial cells, yeast and hyphae. Aspergillus spp grew in the culture of deep tracheal aspirate sample, the results of the biochemical parameters were as follows: BUN: $132.7 \mathrm{mg} / \mathrm{dl}$, creatinine: $3.39 \mathrm{mg} / \mathrm{dl}$, CRP: $4.18 \mathrm{mg} / \mathrm{L}$, procalcitonin: $0.60 \mathrm{ng} / \mathrm{ml}$, calcium: $7.87 \mathrm{mg} / \mathrm{dl}$. Other results were found in the normal range. The patient was treated in the nephrology department.
\end{abstract}

Keywords: Aspergillus spp; Renal Failure; Pulmonary Aspergillosis

\section{Introduction}

Aspergillus spp is a fungus that can cause invasive disease in immunocompromised patients. Aspergillus fumigatus is the most common isolate obtained in $70-90 \%$ of invasive aspergillosis (IA) cases in immunocompromised patients. Aspergillus spp are mainly respiratory pathogens [1]. Invasive aspergillosis occurs predominantly in immunocompromised hosts, such as hematological malignancies, hematopoietic stem cell or solid organ transplants, congenital or acquired immunodeficiency, and other immunosuppressive drugs $[2,3]$. Infections are usually caused by hematogenous propagation through a focus, such as lung infection, or by direct extension from the paranasal sinuses rarely $[4,5]$.

\section{Case Presentation}

We report a case of invasive pulmonary aspergillosis Figure 1, in a man with pre-diagnosis of chronic obstructive pulmonary disease, unspecified chronic renal failure, complaints of cough and respiratory distress at 84 years of age and primary hypertension, chronic obstructive lung disease, unspecified preliminary diagnoses. In the microscope of deep tracheal aspirate specimen taken from the patient; rare leukocytes (PMNL), 1-2 epithelial cells, yeast and hyphae were seen. Aspergillus spp grew on blood culture of deep tracheal aspirate specimen Figure 2, and it, was seen with methylene blue (Figure 3). The patient was treated at the nephrology department. Her blood level was $10 \mathrm{~g} / \mathrm{dl}$, her white blood cell count (WBC) was $9850 / \mathrm{mm}^{3}$ and her platelet count was $222 / \mathrm{mm}^{3}$. The results of the biochemical parameters were as follows: BUN: $132.7 \mathrm{mg} / \mathrm{dl}$, creatinine: $3.39 \mathrm{mg} /$ dl, CRP: $4.18 \mathrm{mg} / \mathrm{L}$, calcium: $7.87 \mathrm{mg} / \mathrm{dl}$. Other results were found in the normal rang. The initiation of therapy in pulmonary diseases, the patient was followed later in the nephrology service.

\section{Discussion}

The aspergillus are ubiquitous fungi whose normal ecological niche is that of a soil saproyphyte and may cause an invasive disease in immunocompromised patients. Aspergillus spp are primarily

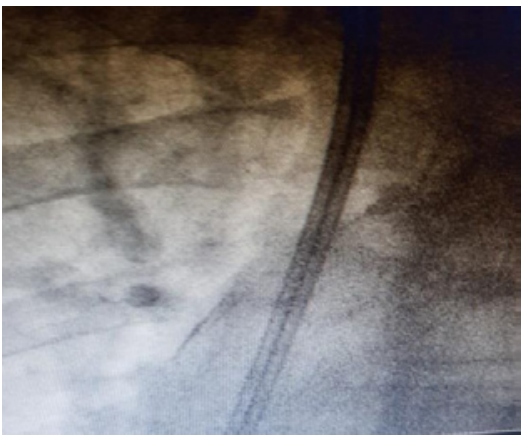

Figure 1: Pulmonary Aspergillosis.

respiratory pathogens, and the lungs constitute the main portal of entry before dissemination [1]. Invasive aspergillosis predominantly occurs in immunocompromised hosts, such as those with hematological malignancies, hematopoietic stem cell or solid organ transplants, congenital or acquired immunodeficiency, as well as use of corticosteroids and other immunosuppressive drugs [2,3]. The infections mostly occur through hematogenous dissemination from a focus, such as lung infection, or rarely through direct extension from the paranasal sinuses $[4,5]$. Case a 84 -year-old man was admitted with a history of respiratory distress and cough of one-week duration. Infections are common in chronic renal failure patients. The mechanisms underlying the defective responses in phagocytic cells, lymphocytes and antigen processing are likely due to either failure to adequately eliminate suppressive compounds by the defective kidneys or to improper metabolic processing of the factors by the damaged renal parenchyma [6,7]. Invasive pulmonary aspergillosis is rare in renal failure and has previously been reported as a few case reports, it may also rarely occur in immunocompetent individuals [8,9]. Our patient had no previous history of the immunodeficiency. Chronic renal failure is thought to be the main cause for immunodisregulation leading to invasive disease in our patient. Aspergillus spp are primarily respiratory pathogens, and the most common clinical signs are high 


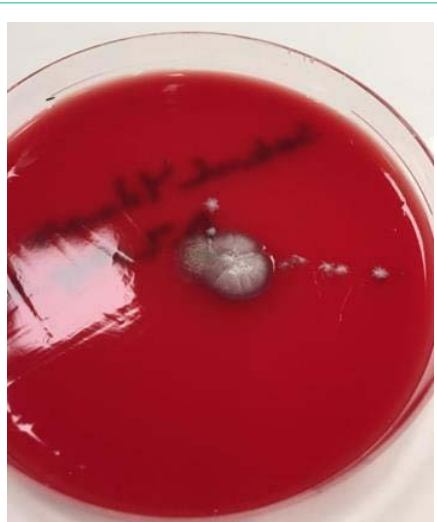

Figure 2: Aspergillus spp grew on blood culture of deep tracheal aspirate specimen.

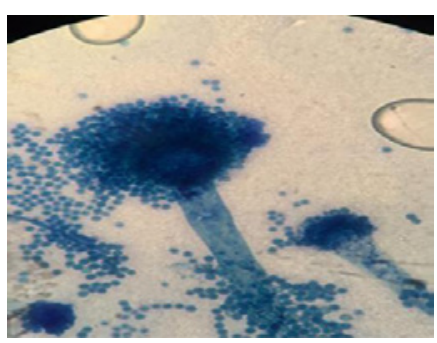

Figure 3: Aspergillus spp was seen with methylene blue.

fever, cough, and expectoration that are unresponsive to empirical treatment. But on the other hand clinical signs can be non-specific, approximately $25-33 \%$ of patients initially have no symptoms attributable to invasive pulmonary aspergillosis [9,10]. Aspergillus spp are primarily respiratory pathogens, and the lungs constitute the main entry before dissemination. The definitive diagnosis is made with microbiological tests (microscopy, stain, culture). The hyphae appearance with branches of $45^{\circ}$ is a typical and specific finding for aspergillus infection $[1,11]$. In conclusion, invasive aspergillosis rarely occurs in immunocompetent patients and diagnosis may be missed or delayed due to lack of the particular clinical signs $[2,10]$. Invasive fungal infections are a major challenge in the management of immunocompromised patients and those with renal dysfunction [11]. These challenges are due to the immense morbidity and mortality in such situations. Also the management strategies for invasive mycosis in patients with renal dysfunction have narrow safety profile and involve high-cost [1]. Invasive pulmonary aspergillosis is probably the most aggressive fungal infection known to man. It occurs mainly in severely immunocompromised patients.

\section{References}

1. Rog EL, Steinbach WJ. Aspergillus. Kliegman BF, Stanton JW, St. Geme NF, Schor RE. Behrman (Eds.). Nelson Textbook of Pediatrics. $19^{\text {th }}$ ed. Elsevier Saunders. Philadelphia. 2011: 1058-1062.

2. Kontoyiannis DP, Bodey GP. Invasive aspergillosis in 2002: An update. Eur J. Clin. Microbiol. Infect. Dis. 2002; 21: 161-172.

3. Denning DW. Invasive aspergillosis. Clin. Infect. Dis. 1998; 26: 781-803.

4. Green M, Wald ER, Tzakis A, Todo S, Starzl TE. Aspergillosis of the CNS in a pediatric liver transplant recipient: Case report and review. Rev. Infect. Dis. 1991; 13: 653-657.

5. Robinson MR, Fine HF, Ross ML, Mont EK, Bryant-Greenwood PK, Hertle RW, et al. Walsh, Sino-orbital-cerebral aspergillosis in immunocompromised pediatric patients. Pediatr. Infect. Dis. J. 2000; 19: 1197-1203.

6. Pesanti EL. Immunologic defects and vaccination in patients with chronic renal failure. Infect. Dis. Clin. N. Am. 2001; 15: 813-832.

7. Sahlen AO, Suvarna SK, Wilkie ME. A case of invasive pulmonary aspergillosis in renal failure. Nephrol. Dial. Transplant. 2004; 19: 2687.

8. Kose S, Cavdar G, Senger SS, Akkoclu G. Central nervous system aspergillosis in an immunocompetent patient. J. Infect. Dev. Ctries. 2011; 5: 313-315.

9. Xu XM, Sun HM, Zhao BL, Shi Y. Diagnosis of airway-invasive pulmonary aspergillosis by tree-in-bud sign in an immunocompetent patient: Case report and literature review. J. Mycol. Méd. 2013; 23: 64-69.

10. Denning DW. Invasive Aspergillosis. Clin. Infect. Dis. 1998; 26: 781-803.

11. Mennink-Kersten MA, Donnelly JP, Verweij PE. Detection of circulating galactomannan for the diagnosis and management of invasive Aspergillosis. Lancet Infect. Dis. 2004; 4: 349-357.
J Bacteriol Mycol - Volume 6 Issue 2 - 2019

ISSN : 2471-0172 | www.austinpublishing group.com

Șahin. (C) All rights are reserved
Citation: Sahin R. A Case of Pulmonary Aspergillus Infection in with a Patient Renal Failure. J Bacteriol Mycol. 2019; 6(2): 1097 